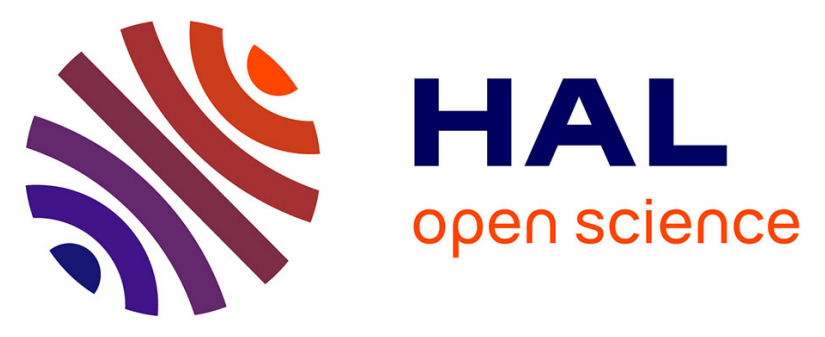

\title{
Pharmacoinvasive Strategy Versus Primary Percutaneous Coronary Intervention for ST-Segment Elevation Myocardial Infarction in Patients $\geq 70$ Years of Age
}

Vincent Auffret, Clément Laurin, Guillaume Leurent, Romain Didier, Emmanuelle Filippi, Jean-Philippe Hacot, Amer Zabalawi, Gilles Rouault, Djamel Saouli, Philippe Druelles, et al.

\section{- To cite this version:}

Vincent Auffret, Clément Laurin, Guillaume Leurent, Romain Didier, Emmanuelle Filippi, et al.. Pharmacoinvasive Strategy Versus Primary Percutaneous Coronary Intervention for ST-Segment Elevation Myocardial Infarction in Patients $\geq 70$ Years of Age. American Journal of Cardiology, 2020, 125 (1), pp.1-10. 10.1016/j.amjcard.2019.09.044 . hal-02440634

HAL Id: hal-02440634

https://hal-univ-rennes1.archives-ouvertes.fr/hal-02440634

Submitted on 11 Feb 2020

HAL is a multi-disciplinary open access archive for the deposit and dissemination of scientific research documents, whether they are published or not. The documents may come from teaching and research institutions in France or abroad, or from public or private research centers.
L'archive ouverte pluridisciplinaire HAL, est destinée au dépôt et à la diffusion de documents scientifiques de niveau recherche, publiés ou non, émanant des établissements d'enseignement et de recherche français ou étrangers, des laboratoires publics ou privés. 


\section{Pharmacoinvasive Strategy Versus Primary Percutaneous Coronary}

\section{Intervention For ST-Segment Elevation Myocardial Infarction In Patients $\geq$}

\section{Years of Age}

Running head: Pharmacoinvasive strategy in older STEMI patients

Vincent Auffret, MD, MSc ${ }^{\mathrm{a}^{*}}$, Clément Laurin, $\mathrm{MD}^{\mathrm{a}, \mathrm{c}^{*}}$, Guillaume Leurent, $\mathrm{MD}^{\mathrm{a}}$, Romain Didier, $\mathrm{MD}^{\mathrm{b}}$, Emmanuelle Filippi, $\mathrm{MD}^{\mathrm{c}}$, Jean-Philippe Hacot, $\mathrm{MD}^{\mathrm{d}}$, Amer Zabalawi, $\mathrm{MD}^{\mathrm{e}}$, Gilles Rouault, $\mathrm{MD}^{\mathrm{f}}$, Djamel Saouli, MD $^{\mathrm{g}}$, Philippe Druelles, $\mathrm{MD}^{\mathrm{h}}$, Isabelle Coudert, $\mathrm{MD}^{\mathrm{i}}$, Bertrand Boulanger, $\mathrm{MD}^{\mathrm{j}}$, Emilie Bot, $\mathrm{MD}^{\mathrm{k}}$, Josiane Treuil, MD ${ }^{1}$, Marc Bedossa, $\mathrm{MD}^{\mathrm{a}}$, Dominique Boulmier, MD ${ }^{\mathrm{a}}$, Aurélie Loirat, MD ${ }^{\mathrm{a}}$, Sam Sharobeem, MSc ${ }^{\mathrm{a}}$, Marielle Le Guellec, $\mathrm{MSc}^{\mathrm{a}}$, Martine Gilard, MD, $\mathrm{PhD}^{\mathrm{b}}$, and Hervé Le Breton MD

\section{Authors' affiliations:}

${ }^{a}$ University of Rennes 1, Cardiology and Vascular Diseases Department, Pontchaillou University Hospital, Center for Clinical Investigation 804, Signal and Image Treatment laboratory (LTSI), National Institute of Health and Medical Research U1099, Rennes, France

${ }^{\mathrm{b}}$ Cardiology Department, La Cavale Blanche University Hospital, Optimization of physiological Regulations, Science and Technical Training and ResearchUnit, Brest, France

${ }^{\mathrm{c}}$ Cardiology Department, General Hospital of Atlantic Brittany, Vannes, France

${ }^{\mathrm{d}}$ Cardiology Department, General Hospital of South Brittany, Lorient, France

${ }^{\mathrm{e}}$ Cardiology Department, General Hospital Yves Le Foll, St-Brieuc, France

${ }^{\mathrm{f}}$ Cardiology Department, General Hospital René Théophile Laennec, Quimper, France ${ }^{g}$ Cardiology Department, General Hospital Broussais, St-Malo, France ${ }^{\mathrm{h}}$ Cardiology Department, Clinic St-Laurent, Rennes, France

${ }^{i}$ Medical Emergency Department, General Hospital Yves Le Foll, St-Brieuc, France ${ }^{j}$ Medical Emergency Department, General Hospital of Atlantic Brittany, Vannes, France

${ }^{\mathrm{k}}$ Medical Emergency Department, Pontchaillou University Hospital, Rennes, France

${ }^{1}$ Medical Emergency Department, La Cavale Blanche University Hospital, Brest, France *VA and CL contributed equally and should be considered co-first author

Conflict of interest: Authors have reported that they have no relationships relevant to the content of this paper to disclose.

\section{Corresponding Author:}

Vincent Auffret, MD, MSc

Cardiology and Vascular Diseases Department

Pontchaillou University Hospital

2 rue Henri Le Guilloux, 35033 Rennes, France.

Phone: + 33299282 505, Fax: +33 299282529

Email: vincent.auffret@chu-rennes.fr 


\begin{abstract}
The benefit-risk ratio of a pharmacoinvasive strategy (PI) among patients $\geq 70$ years of age with ST-segment elevation myocardial infarction (STEMI) remains uncertain resulting in its limited use in this population. This study compared efficacy and safety of PI with primary percutaneous coronary intervention (pPCI). Data from 2841 patients (mean age: $78.1 \pm 5.6$ years, female: $36.1 \%$ ) included in a prospective multicenter registry, and who underwent either PI $(n=269)$ or pPCI $(n=2572)$, were analyzed. The primary endpoint was in-hospital major adverse cardiovascular events (MACE) defined as the composite of all-cause mortality, non-fatal MI, stroke and definite stent thrombosis. Secondary endpoints included all-cause death, major bleeding, net adverse clinical events and the development of in-hospital Killip class III or IV heart failure. Propensityscore matching and conditional logistic regression were used to adjust for confounders. Within the matched cohort, rates of MACE was not statistically different between the PI $(n=247)$ and pPCI ( $\mathrm{n}=958)$ groups, $(11.3 \%$ vs. $9.0 \%$ respectively, OR: $1.25,95 \%$ CI: $0.81-1.94 ; \mathrm{p}=0.31)$. Secondary endpoints were comparable between groups at the exception of a lower rate of development of Killip class III or IV heart failure after PI. The rate of intracranial hemorrhage was significantly higher in the PI group $(2.3 \%$ vs. $0.0 \%, p=0.03)$. In conclusion, the present study demonstrated no difference regarding in-hospital MACE following PI or pPCI in STEMI patients $\geq 70$ years of age. An adequately-powered randomized trial is needed to precisely define the role of PI in this high-risk subgroup.
\end{abstract}

Key words: STEMI; older patients; pharmacoinvasive strategy; primary percutaneous coronary intervention 


\section{INTRODUCTION}

Guidelines for patients with ST-segment elevation myocardial infarction (STEMI) recommend timely primary percutaneous coronary intervention (pPCI) as the preferred reperfusion strategy(1). If timely pPCI cannot be performed, a pharmacoinvasive strategy (PI) is recommended within $12 \mathrm{~h}$ of symptom onset in patients without contraindications (2-4). Largest benefits are seen among early presenters $(<2-3 \mathrm{~h}$ of symptom onset) with anterior STEMI (5). Older patients have a higher STEMI-related morbi-mortality (6), and remain undertreated or subject to major delays to pPCI (7). To date, only few studies specifically reported the outcomes of PI among older patients with STEMI because they were often excluded from randomized trials therefore resulting in an uncertain benefit/risk ratio (8). Although age per se is not an absolute contraindication in guidelines (9), this results in a lower use of PI in older patients in clinical practice mainly owing to the reluctance of physicians to use such a therapy in these patients usually at higher bleeding risk. The present study compares efficacy and safety of PI with pPCI in patients $\geq 70$ years of age enrolled in a large prospective registry.

\section{METHODS}

This observational study used data from the Brittany Regional Infarction Observatory (Observatoire Régional Breton sur l'Infarctus, ORBI) that prospectively includes from 2006 all patients admitted to one of 9 participating pPCI-capable centers for STEMI, within $24 \mathrm{~h}$ of symptom onset (10). The centralized database used for the present study contains demographic and electrocardiographic data, treatments, time intervals and in-hospital events. This registry was approved by the Commission Nationale de l'Informatique et des Libertés and the study protocol was approved by the local ethics committee. Patients enrolled in ORBI between June 2006 and June 2016, aged $\geq 70$ years old and treated by PI or pPCI were included in this analysis and compared. Patients aged $\geq 70$ years old who received no reperfusion therapy at the acute phase 
regardless of the performance of coronary angiography or secondary PCI during the index hospitalization were excluded from the analysis (Figure 1).

STEMI was defined according to the universal definition of myocardial infarction (11). First medical contact (FMC) was defined as the time point when the patient was assessed by a physician able to obtain, and interpret an electrocardiogram, and deliver the appropriate initial interventions (9). FMC-to-pPCI delay was defined as the time from FMC to the first thromboaspiration or balloon inflation. Total ischemic time was defined as the time between symptom's onset and pPCI or fibrinolysis (i.e. start of the fibrinolytic infusion). FMC-totreatment delay was categorized according to the 2012 European STEMI guidelines (12) as beyond guidelines delay if $>30 \mathrm{~min}$ in patients treated by fibrinolysis, $>60 \mathrm{~min}$ in patients directly admitted to a pPCI-capable center, and > $120 \mathrm{~min}$ in the other patients treated by pPCI. Development of in-hospital Killip class III or IV heart failure was defined as a maximum Killip class III or IV at any time during the index hospitalization among patients with Killip class I or II at admission. Killip class was determined by local investigators in charge of the patients. Mechanical circulatory assistances included intra-aortic balloon pump, extra-corporeal membrane oxygenation and the Impella left ventricular assist device (Abiomed, Danvers, MA). Mechanical complication was defined as the occurrence of either ischemic mitral regurgitation or ventricular septal rupture. High-degree atrioventricular block was defined as third or second-degree type 2 atrioventricular blocks.

Patients were managed according to participating centers' local protocols, which followed European guidelines at use at the time of patient's enrollment. Consequently, among patients who received PI, a full-dose of a fibrin-specific agent (tenecteplase: 96\%; reteplase: 4\%) was administered regardless of age as the study period predated the recent class IIaB recommendation of using a half-dose tenecteplase in patients $\geq 75$ years of age (9). The choice of guidelinesrecommended co-therapies (antiplatelet and anticoagulant drugs) was left at the discretion of the attending physician. 
The primary endpoint of the study was in-hospital major adverse cardiovascular events (MACE), defined as the composite of all-cause mortality, non-fatal MI, stroke and definite stent thrombosis (ST) according to the Academic Research Consortium definition. Secondary endpoints included all-cause death, major bleeding recorded since the inclusion of the Bleeding Academic Research Consortium (BARC) definition in the ORBI database in 2011 and defined as BARC 3 or 5 bleeding, net adverse clinical events (NACE) defined as the composite of MACE and major bleeding, and calculated among patients with data regarding in-hospital BARC-defined bleeding events, and development of in-hospital Killip class III or IV heart failure.

Categorical variables were summarized as number (percentages) and compared using Chisquare or Fisher exact tests. Continuous variables were expressed as median (interquartile range, IQR) and compared using the Mann-Whitney test. The primary analysis was performed using propensity score-matching(13). The propensity-score was developed using a non-parsimonious logistic regression model with the reperfusion strategy as the dependent variable and including all baseline characteristics listed in Table 1 at the exception of the GRACE and TIMI scores which include numerous characteristics already listed in Table 1. The c-statistic of the model of 0.81 (95\% confidence interval $[\mathrm{CI}]: 0.78-0.84)$ showed good discrimination with adequate calibration (Hosmer-Lemeshow $\mathrm{p}=0.21$ ). A 1-to-5 nearest neighbor matching without replacement with a caliper of $0.2 \mathrm{x}$ SD (logit of the propensity score) was performed. The balance between matched groups was evaluated by the analysis of the standardized differences before and after matching. An absolute value of $<0.1$ after matching was considered an adequate reduction of baseline imbalance. In the matched population, multivariable conditional logistic regression was used to calculate adjusted odds-ratio (OR) with their corresponding 95\% CI for reperfusion strategies regarding the occurrence of the endpoints while adjusting for admission to a non-PCI capable hospital, which despite adequate reduction of baseline imbalance as assessed by standardized differences demonstrated a significant absolute numerical difference between matched groups. As 
a sensitivity analysis, a propensity score-adjusted logistic regression was performed in the entire population to confirm the results of the primary analysis. In this analysis, missing data were assumed to be missing at random and handled by chained equations multiple imputations. Overall, $1.6 \%$ of data were missing and a total of $23.3 \%$ of patients had at least 1 missing value. Ten complete datasets were generated and the propensity score was calculated within each dataset using the above described methodology. Multivariable logistic regression adjusted on the propensity score was then performed. Results were expressed as adjusted OR (95\% CI) and pooled using Rubin's rule. Statistical analysis was performed with the use of Statistical Package for Social Sciences version 22 (SPSS, Chicago, IL, USA). All tests were 2-sided at the 0.05 significance level.

\section{RESULTS}

A total of 2841 patients (mean age: $78.1 \pm 5.6$ years; female: $36.1 \%$ ) aged $\geq 70$ years old were included, among them 269 patients underwent PI and 2572 were treated by pPCI (Figure 1). Patients $\geq 90$ years of age represented $1.1 \%$ and $3.2 \%$ of the PI and pPCI group, respectively $(\mathrm{p}=0.06)$. Baseline characteristics and in-hospital outcomes of patients who received no reperfusion therapy are compared with those of patients who received reperfusion therapy (either PCI or fibrinolysis) in supplementary Tables 1 and 2. The management strategy evolved over time with an increasing rate of pPCI from $78 \%$ in 2006-2007 to $95 \%$ in 2014-2016. During the study period, a non-significant trend towards a lower symptom's onset-to-FMC delay was observed (Jonckheere-Terpstra test $\mathrm{p}=0.085$ ). However, no such trend was apparent for the FMCto-pPCI delay $(\mathrm{p}=0.93)$. There was no significant difference in rates of patients treated within guidelines-recommended delays over time $(\mathrm{p}=0.84)$. Patients with a symptom's onset-to-FMC delay $>12 \mathrm{~h}$ represented only $2.9 \%$ and $0.8 \%$ of $\mathrm{pPCI}$ and PI patients, respectively $(\mathrm{p}=0.06)$. Total ischemic time was significantly lower among PI patients: 180 (115-280) min vs. 227 (165-335) $\min (\mathrm{p}<0.001)$. Baseline characteristics of patients are listed in table 1. Procedural and in-hospital 
management of the study population are described in table 2 . The median delays from failed fibrinolysis to angiography, and PCI were $115 \mathrm{~min}$ (98.5-162.5), and $138 \mathrm{~min}$ (110-185), respectively. The median delays between successful fibrinolysis and angiography, and PCI were $260 \min (115-1500)$, and 1185 (152-2785), respectively.

MACE occurred in 31 patients (11.5\%) in the PI group compared with 270 patients $(10.5 \%)$ in the pPCI group $(\mathrm{p}=0.68)$ (Table 3). There was no significant interaction between the reperfusion strategy and age group or total ischemic time regarding the occurrence of MACE (Figure 2). Patients requiring rescue PCI had numerically higher rates of in-hospital adverse events than patients with successful fibrinolysis or Ppci (Supplementary Table 3). Supplementary Table 4 provides a comparison of baseline characteristics of patients with and without data regarding BARC-defined bleeding events. BARC-defined major bleeding and NACE were numerically higher in PI recipients $(7.0 \%$ vs. $4.5 \%, \mathrm{p}=0.28$ and $17.4 \%$ vs. $13.8 \%, \mathrm{p}=0.44$, respectively). Of note, rates of intracranial hemorrhage were significantly higher in the fibrinolysis group (2.3\% vs. $0.3 \%, \mathrm{p}=0.04)$. Supplementary Table 5 summarizes bleeding sites according to treatment group. As an exploratory analysis, we compared the characteristics of PI patients with and without MACE (supplementary table 6). Patients who experienced MACE tended to have more diabetes mellitus, more often presented with a history of myocardial infarction, and with severe heart failure on admission. They also had higher levels of serum creatinine, and glycemia on admission, and higher GRACE, and TIMI STEMI risk scores.

Among pPCI patients, the rate of development of Killip class III or IV heart failure was higher $(8.6 \%)$ than in PI patients $(3.4 \%, \mathrm{p}=0.004)$. This trend was more pronounced among patients with anterior STEMI (12.0\% vs. 4.2\%, p=0.013) compared with their non-anterior STEMI counterparts $(6.1 \%$ vs. $2.7 \%, \mathrm{p}=0.098)$. Moreover, the FMC-to-pPCI delay was longer among pPCI patients who developed (median $114 \mathrm{~min}$, IQR: 85-150 min) compared with those who did not developed severe heart failure (median $102 \mathrm{~min}$, IQR: 80-139 min, $\mathrm{p}=0.018$ ), whereas 
symptom's onset-to-FMC delays were comparable (median:118 min, IQR: 60-235 min vs. median:105 min, IQR:60-199 min, respectively; $\mathrm{p}=0.42$ ).

A total 247 patients from the PI group and 958 from the pPCI group whose baseline and procedural characteristics are listed in supplementary tables $\mathbf{7}$ and $\mathbf{8}$ were included in the matched cohort. The rate of MACE was not statistically different between the PI and pPCI groups, (11.3\% vs. 9.0\% respectively, OR:1.25, 95\% CI: 0.81-1.94; p=0.31) (table4, Figure 3). Secondary endpoints were comparable between groups at the exception of a significant difference for the development of Killip class III or IV heart failure favoring the PI group (3.3\% vs 9.3\%, OR: $0.38,95 \% \mathrm{CI}: 0.18-0.79 ; \mathrm{p}=0.01)$. There was no significant interaction between treatment effect and total ischemic time (supplementary table 9). Two intracranial hemorrhages occurred, both in the PI group ( $2.3 \%$ vs. $0.0 \%, \mathrm{p}=0.03)$. Propensity score-adjusted logistic regression was performed in the entire cohort and confirmed the primary analysis results for the primary endpoint $(\mathrm{OR}=1.23,95 \% \mathrm{CI}: 0.78-1.91 ; \mathrm{p}=0.37)$ and for secondary endpoints (supplementary Table 10).

\section{DISCUSSION}

This analysis of data from a large prospective registry provides valuable insights regarding the use of PI in a STEMI population $\geq 70$ years of age which constitutes a large and growing proportion of STEMI patients. The main findings can be summarized as follows: first, PI use was infrequent in older patients, performed in only $9.4 \%$ of patients aged $\geq 70$ years old. Second, PI use dramatically decreased over the decade studied from $22 \%$ to $5 \%$. Third, no difference was observed in MACE and all-cause death between reperfusion strategies. Fourth, in an analysis limited to half of the population, no significant difference was demonstrated in major bleeding between pPCI and PI recipients, although intracranial hemorrhage was more frequent following PI. Fifth, pPCI associated with an increase rate of in-hospital development of severe heart failure. 
A significant heterogeneity in reperfusion strategies across countries has been reported in a recent European survey with rates of fibrinolysis ranging from 0 to $55 \%$ (14). Therefore, providing contemporary data regarding outcomes of PI remains crucial, especially for countries that do not have the pPCI infrastructure or are not able to use it sufficiently to treat the majority of their STEMI patients. Within the French national registry, FAST-MI (15), a gradual decrease in the use of fibrinolysis was observed over time from $37.5 \%$ of STEMI patients in 1995 to $6 \%$ in 2015. This trend likely reflects improvements in emergency care networks with a higher availability of pPCI. However, it may also translate a certain reluctance of clinicians to perform PI owing to its potentially life-threatening side effects, especially in older patients.

Establishing the efficacy and safety of PI among older patients may be of paramount importance to reduce the proportion of patients who do not benefit from any reperfusion therapy. The TRIANA trial attempted to address this unmet need but was terminated early after enrollment of approximately half ( $\mathrm{n}=266$ patients $\geq 75$ years old with STEMI $<6 \mathrm{~h}$ ) of the estimated population. pPCI resulted in a non-significant $30 \%$ reduction in the 30-day primary composite endpoint of all-cause mortality, re-infarction, or disabling stroke, compared with fibrinolysis, which is comparable to the present study. Nonetheless, a pooled analysis with two previous reperfusion trials performed in older patients showed the superiority of pPCI over fibrinolysis (without widespread use of coronary angiography and secondary PCI) in reducing death, reinfarction, or stroke at 30 days, suggesting that a lack of statistical power likely impeded the demonstration of significant differences in individual studies (16).

The STrategic Reperfusion Early After Myocardial infarction (STREAM) trial specifically compared a contemporary pharmacoinvasive strategy with pPCI (2) in 1892 patients with STEMI presenting within 3 hours of symptom onset, and in whom pPCI was not feasible within 60min of FMC. This trial established clinical equipoise between PI with a weight-adjusted dose of tenecteplase and pPCI. The 30-day primary endpoint of death, cardiogenic shock, congestive heart 
failure, or reinfarction occurred in $12.4 \%$ of the PI recipients and $14.3 \%$ of their pPCI counterparts $(\mathrm{p}=0.21)$. Among patients $\geq 75$ years old, the primary endpoint occurred in $26.9 \%$ of patients in the PI group and in $29.2 \%$ of patients in the pPCI group ( $\mathrm{p}=0.68)$. Importantly, the original trial protocol was amended after $21 \%$ of the intended enrollment to allow halving the bolus of tenecteplase for patients aged $\geq 75$ years because of a high intracranial hemorrhage rate (7.1\%). This strategy resulted in a $0 \%$ intracranial hemorrhage rate post-amendment, whereas indices of reperfusion and rates of rescue pPCI were comparable to that achieved with full-dose tenecteplase. These data contributed to the recent class IIaB recommendation of using a half-dose tenecteplase in patients $\geq 75$ years of age in the latest European Society of Cardiology Guidelines (9). The inclusion period of the present study predating this recommendation, patients received a standard lytic dose, which may explain the crucial finding of a higher rate of intracranial hemorrhage. However, confirmation in a dedicated randomized clinical trial in older adults is required, and will be the purpose of the STrategic Reperfusion in Elderly Patients Early After Myocardial Infarction trial (STREAM-2, NCT 02777580).

A lower risk of development of severe acute heart failure associated with the fibrinolysis strategy was observed in the present analysis. Acute heart failure should be taken under consideration when discussing the reperfusion strategy, especially when the predictable pPCIinduced delay is prolonged $(17,18)$. Indeed, the main advantage of PI is its rapid initiation, while pPCI may expose to major delays $(19,20)$. The impact of such a pPCI-related delay has been wellevaluated in randomized trials in which this time is relatively limited, yet, in clinical practice it seems to be more prolonged (21). A recent meta-analysis of 33 studies reported a $4 \%$ to $12 \%$ increased risk of new-onset heart failure and a $4 \%$ relative increase of incident heart failure during follow-up with every 1-hour delay in time to reperfusion (22). Moreover, a meaningful association between longer pPCI-related delays and increased mortality, the survival advantage of pPCI over PI declining in parallel, has been demonstrated (19). Therefore, pPCI may be overused (or misused) in the contemporary era, especially in transferred patients. Indeed, a recent meta- 
analysis of 17 studies demonstrated a $48 \%$ increased risk of cardiogenic shock associated with the use of pPCI compared with PI among patients transferred from non-pPCI capable hospitals (23). Nonetheless, it should be stressed that, regardless of the reperfusion strategy used, a majority of patients included in the present analysis did not meet the ESC guidelines FMC-to-treatment goals. This prolonged delay, previously observed with both reperfusion strategies among older patients (24), likely highlights clinicians' apprehension of reperfusion therapies despite their welldemonstrated absolute benefit in these high-risk individuals. Continuous efforts are needed to further improve the performance of timely reperfusion in older patients.

Some limitations should be acknowledged. Given the retrospective non-randomized design of this analysis, patients included in the PI group likely represent selected "low-risk" patients deemed suitable for PI following physicians' assessment. Propensity score matching does not balance unmeasured confounders, which likely contributed to the reperfusion strategy's selection, between treatment groups. The present study may not be generalizable to all older patients and should not be regarded as supportive of the widespread use of PI in this population. Loading doses of anti-thrombotic treatments were not systematically reported in the database. Given the inclusion period, the proportion of drug-eluting stents was low, which may have impacted the results. Major bleeding were recorded since the inclusion of the BARC definition in the ORBI database in 2011, allowing us to analyze the safety of PI in a limited number of patients. Therefore, a lack of statistical power regarding certain endpoints (e.g. stroke, major bleeding) cannot be ruled out. On the contrary, p-values were not adjusted for multiple comparisons, which implies a risk of type I error regarding other findings (e.g. in-hospital heart failure). We observed a higher rate of intracranial hemorrhage among patients receiving PI, which may reflect the use of full-dose lytics. Nonetheless, important baseline differences between patients treated in routine practice and those included in randomized trials may also explain this detrimental association, which would suggest that we need more stringent selection criteria when considering PI among older patients. 


\section{ACKNOWLEDGMENTS}

The authors are indebted to all physicians and clinical research assistants that ensured data collection and monitoring of the ORBI registry. 
1. Keeley EC, Boura JA, Grines CL. Primary angioplasty versus intravenous thrombolytic therapy for acute myocardial infarction: a quantitative review of 23 randomized trials. Lancet $2003 ; 361: 13-20$.

2. Armstrong PW, Gershlick AH, Goldstein P, Wilcox R, Danays T, Lambert Y, Sulimov V, Rosell Ortiz F, Ostojic M, Welsh RC, Carvalho AC, Nanas J, Arntz HR, Halvorsen S, Huber K, Grajek S, Fresco C, Bluhmki E, Regelin A, Vandenberghe K, Bogaerts K, Van de Werf F, STREAM Investigative Team. Fibrinolysis or primary PCI in ST-segment elevation myocardial infarction. N Engl J Med 2013;368:1379-1387.

3. Danchin N, Blanchard D, Steg PG, Sauval P, Hanania G, Goldstein P, Cambou JP, Guéret P, Vaur L, Boutalbi Y, Genès N, Lablanche JM; USIC 2000 Investigators. Impact of prehospital thrombolysis for acute myocardial infarction on 1-year outcome: results from the French Nationwide USIC 2000 Registry. Circulation 2004;110:1909-1915.

4. Bonnefoy E, Steg PG, Boutitie F, Dubien PY, Lapostolle F, Roncalli J, Dissait F, Vanzetto G, Leizorowicz A, Kirkorian G; CAPTIM Investigators. Comparison of primary angioplasty and pre-hospital fibrinolysis in acute myocardial infarction (CAPTIM) trial: a 5-year follow-up. Eur Heart J 2009;30:1598-1606.

5. Boersma E, Maas AC, Deckers JW, Simoons ML. Early thrombolytic treatment in acute myocardial infarction: reappraisal of the golden hour. Lancet 1996;348:771-775.

6. Alexander KP, Newby LK, Armstrong PW, Cannon CP, Gibler WB, Rich MW, Van de Werf F, White HD, Weaver WD, Naylor MD, Gore JM, Krumholz HM, Ohman EM. Acute coronary care in the elderly, part II: ST-segment-elevation myocardial infarction: a scientific statement for healthcare professionals from the American Heart Association Council on Clinical Cardiology: in collaboration with the Society of Geriatric Cardiology. Circulation 2007;115:2570-2589. 
7. Rosengren A, Wallentin L, Simoons M, Gitt AK, Behar S, Battler A, Hasdai D. Age, clinical presentation, and outcome of acute coronary syndromes in the Euroheart acute coronary syndrome survey. Eur Heart J 2006;27:789-795.

8. Koeth O1, Zahn R, Gitt AK, Bauer T, Juenger C, Senges J, Zeymer U. Clinical benefit of early reperfusion therapy in patients with ST-elevation myocardial infarction usually excluded from randomized clinical trials (results from the Maximal Individual Therapy in Acute Myocardial Infarction Plus [MITRA Plus] registry). Am J Cardiol 2009;104:1074-1077.

9. Ibanez B, James S, Agewall S, Antunes MJ, Bucciarelli-Ducci C, Bueno H, Caforio ALP, Crea F, Goudevenos JA, Halvorsen S, Hindricks G, Kastrati A, Lenzen MJ, Prescott E, Roffi M, Valgimigli M, Varenhorst C, Vranckx P, Widimský P. 2017 ESC Guidelines for the management of acute myocardial infarction in patients presenting with ST-segment elevation. Eur Heart J 2018;39:119-177

10. Auffret V, Cottin Y, Leurent G, Gilard M, Beer JC, Zabalawi A, Chagué F, Filippi E, Brunet D, Hacot JP, Brunel P, Mejri M, Lorgis L, Rouault G, Druelles P, Cornily JC, Didier R, Bot E, Boulanger B, Coudert I, Loirat A, Bedossa M, Boulmier D, Maza M, Le Guellec M, Puri R, Zeller M, Le Breton H. Predicting the development of in-hospital cardiogenic shock in patients with ST-segment elevation myocardial infarction treated by primary percutaneous coronary intervention: the ORBI risk score. Eur Heart J 2018;39:2090-2102.

11. Thygesen K, Alpert JS, Jaffe AS, Chaitman BR, Bax JJ, Morrow DA, White HD; ESC Scientific Document Group. Fourth universal definition of myocardial infarction. Eur Heart J 2019;40:237-269.

12. Steg PG, James SK, Atar D, Badano LP, Blömstrom-Lundqvist C, Borger MA, Di Mario C, Dickstein K, Ducrocq G, Fernandez-Aviles F, Gershlick AH, Giannuzzi P, Halvorsen S, Huber K, Juni P, Kastrati A, Knuuti J, Lenzen MJ, Mahaffey KW, Valgimigli M, van 't Hof 
A, Widimsky P, Zahger D. ESC Guidelines for the management of acute myocardial infarction in patients presenting with ST-segment elevation. Eur Heart J 2012;33:2569-2619.

13. Heinze G, Jüni P. An overview of the objectives of and the approaches to propensity score analyses. Eur Heart J 2011;32:1704-1708.

14. Widimsky P1, Wijns W, Fajadet J, de Belder M, Knot J, Aaberge L, Andrikopoulos G, Baz JA, Betriu A, Claeys M, Danchin N, Djambazov S, Erne P, Hartikainen J, Huber K, Kala P, Klinceva M, Kristensen SD, Ludman P, Ferre JM, Merkely B, Milicic D, Morais J, Noc M, Opolski G, Ostojic M, Radovanovic D, De Servi S, Stenestrand U, Studencan M, Tubaro M, Vasiljevic Z, Weidinger F, Witkowski A, Zeymer U. Reperfusion therapy for ST elevation acute myocardial infarction in Europe: description of the current situation in 30 countries. Eur Heart J 2010;31:943-957.

15. Belle L, Cayla G, Cottin Y, Coste P, Khalife K, Labèque JN, Farah B, Perret T, Goldstein P, Gueugniaud PY, Braun F, Gauthier J, Gilard M, Le Heuzey JY, Naccache N, Drouet E, Bataille V, Ferrières J, Puymirat E, Schiele F, Simon T, Danchin N; FAST-MI 2015 investigators. French Registry on Acute ST-elevation and non-ST-elevation Myocardial Infarction 2015 (FAST-MI 2015). Design and baseline data. Arch Cardiovasc Dis $2017 ; 110: 366-378$.

16. Bueno H, Betriu A, Heras M, Alonso JJ, Cequier A, García EJ, López-Sendón JL, Macaya C, Hernández-Antolín R; TRIANA Investigators. Primary angioplasty vs. fibrinolysis in very old patients with acute myocardial infarction: TRIANA (TRatamiento del Infarto Agudo de miocardio eN Ancianos) randomized trial and pooled analysis with previous studies. Eur Heart J 2011;32:51-60.

17. Steg PG, Bonnefoy E, Chabaud S, Lapostolle F, Dubien PY, Cristofini P, Leizorovicz A, Touboul P. Impact of time to treatment on mortality after prehospital fibrinolysis or primary 
angioplasty: data from the CAPTIM randomized clinical trial. Circulation 2003;108:28512856.

18. Auffret V, Leurent G, Gilard M, Hacot JP, Filippi E, Delaunay R, Rialan A, Rouault G, Druelles P, Castellant P, Coudert I, Boulanger B, Treuil J, Bot E, Bedossa M, Boulmier D, Le Guellec M, Donal E, Le Breton H. Incidence, timing, predictors and impact of acute heart failure complicating ST-segment elevation myocardial infarction in patients treated by primary percutaneous coronary intervention. Int J Cardiol 2016;221:433-442.

19. Pinto DS, Kirtane AJ, Nallamothu BK, Murphy SA, Cohen DJ, Laham RJ, Cutlip DE, Bates ER, Frederick PD, Miller DP, Carrozza JP Jr, Antman EM, Cannon CP, Gibson CM. Hospital delays in reperfusion for ST-elevation myocardial infarction: implications when selecting a reperfusion strategy. Circulation 2006;114:2019-2025.

20. GUSTO Angiographic Investigators. The effects of tissue plasminogen activator, streptokinase, or both on coronary-artery patency, ventricular function, and survival after acute myocardial infarction. N Engl J Med 1993;329:1615-1622.

21. Nallamothu BK, Bates ER, Herrin J, Wang Y, Bradley EH, Krumholz HM. Times to treatment in transfer patients undergoing primary percutaneous coronary intervention in the United States: National Registry of Myocardial Infarction (NRMI)-3/4 analysis. Circulation 2005; 111:761-767.

22. Goel K, Pinto DS, Gibson CM. Association of time to reperfusion with left ventricular function and heart failure in patients with acute myocardial infarction treated with primary percutaneous coronary intervention: a systematic review. Am Heart J 2013;165:451-467.

23. Siddiqi TJ, Usman MS, Khan MS, Sreenivasan J, Kassas I, Riaz H, Raza S, Deo SV, Sharif H, Kalra A, Yadav N. Meta- Analysis Comparing Primary Percutaneous Coronary 
Intervention Versus Pharmacoinvasive Therapy in Transfer Patients with ST-Elevation Myocardial Infarction. Am J Cardiol 2018;122:542-547

24. Armstrong PW, Zheng Y, Westerhout CM, Rosell-Ortiz F, Sinnaeve P, Lambert Y, Lopes RD, Bluhmki E, Danays T, Van de Werf F. Reduced dose tenecteplase and outcomes in elderly ST-segment elevation myocardial infarction patients: Insights from the STrategic Reperfusion Early After Myocardial infarction trial. Am Heart J 2015;169:890-898. 


\section{FIGURES LEGEND}

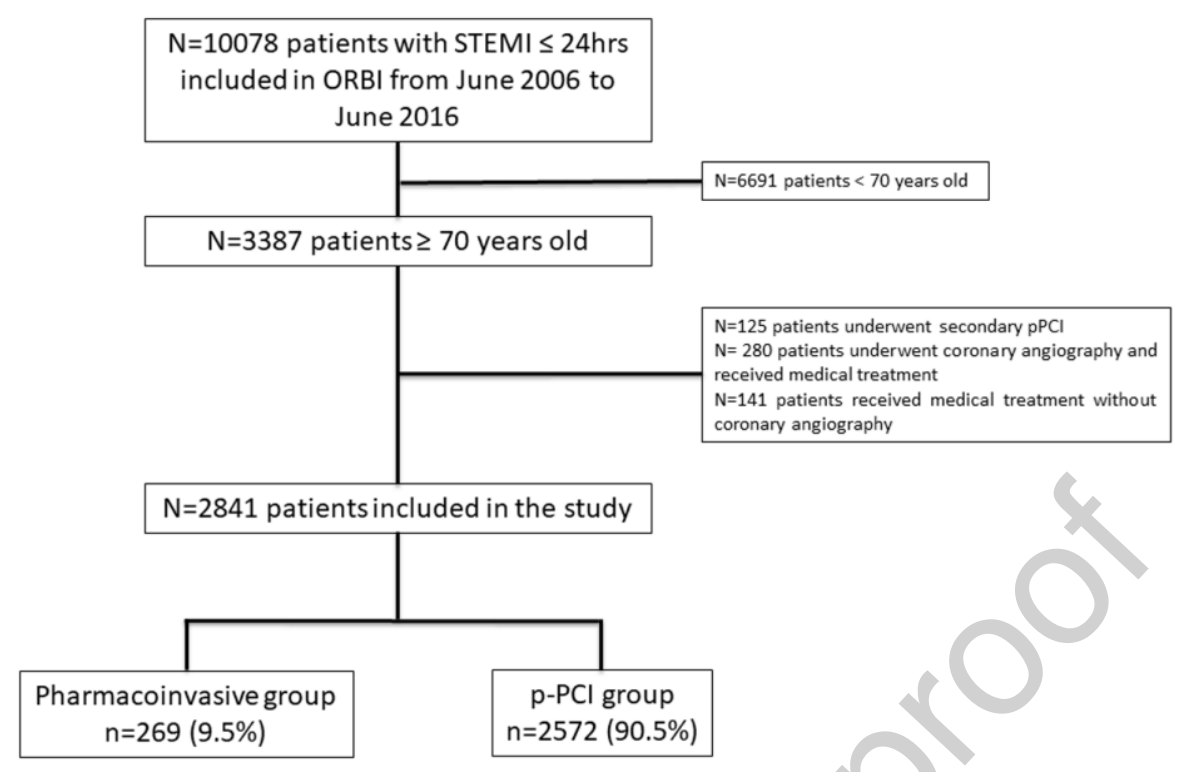

Figure 1- Flow-chart of the study population

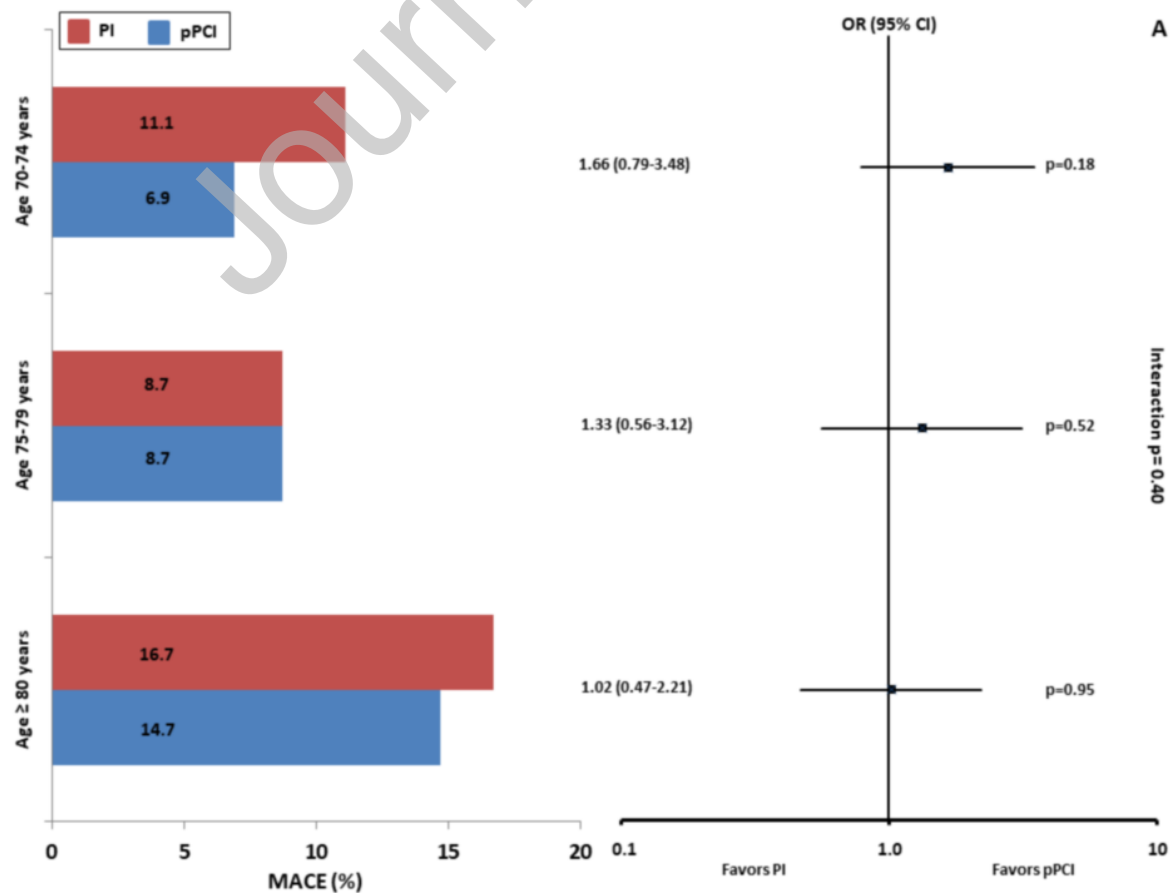




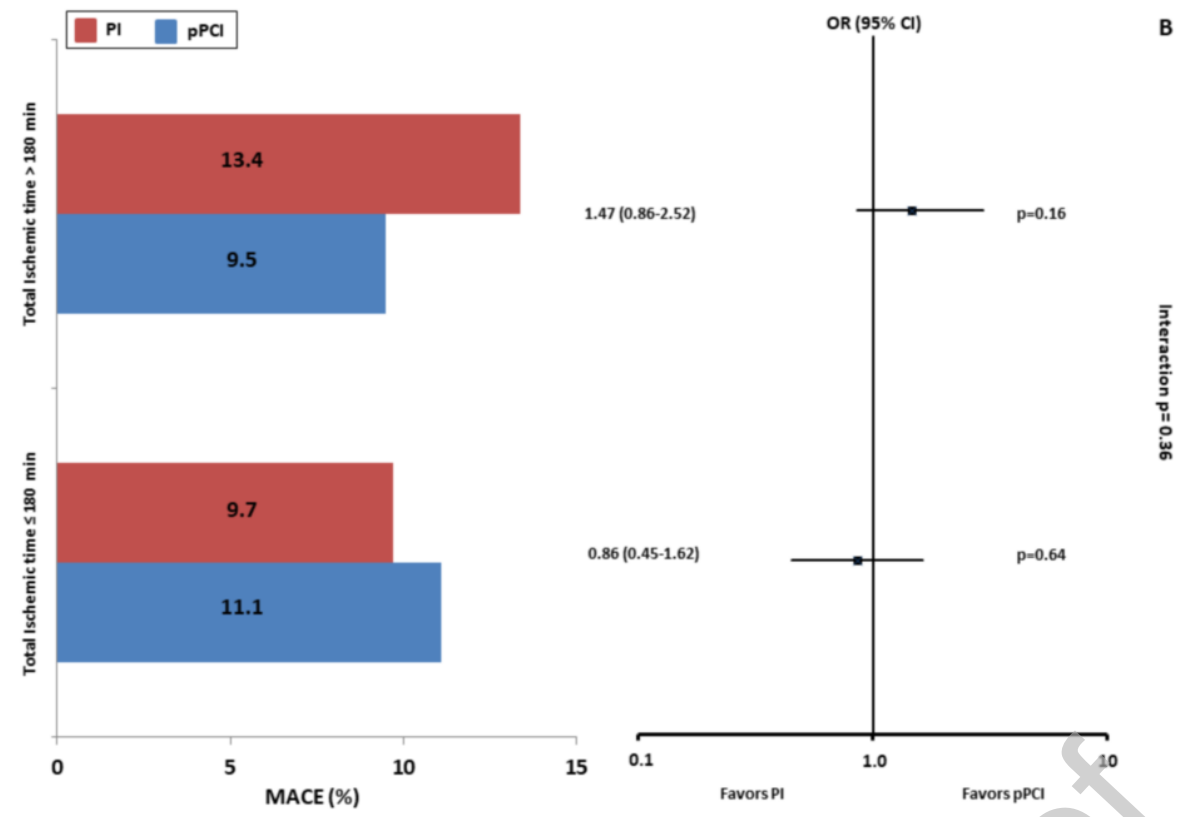

\section{Figure 2- MACE rates among subgroups}

Panel A: MACE rates according to age groups. Panel B: MACE rates according to total ischemic time.

FMC: First medical contact; MACE: Major adverse cardiovascular events; PI: Pharmacoinvasive strategy; pPCI: Primary percutaneous coronary intervention. 


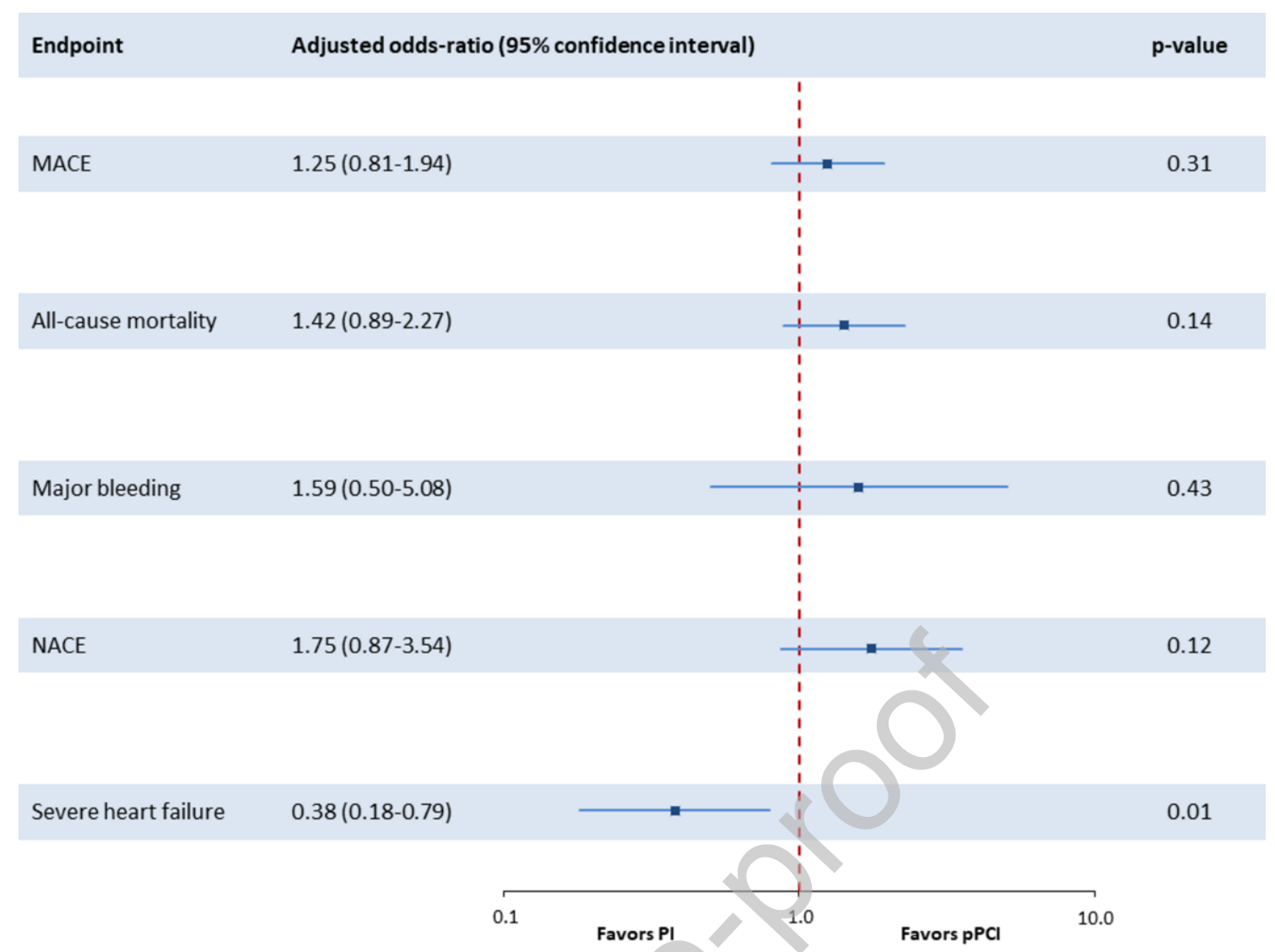

Figure 3- Results of the primary analysis regarding the primary and secondary endpoints.

Results of multivariable conditional logistic regression in the matched cohort regarding the primary and secondary endpoints.

MACE: Major adverse cardiovascular events; NACE: Net adverse clinical events; PI: Pharmacoinvasive strategy; pPCI: Primary percutaneous coronary intervention.

\begin{tabular}{lccc}
\hline \multicolumn{4}{c}{ Table 1 - Baseline characteristics of the study population } \\
\hline Variables & $\begin{array}{c}\text { Pharmacoinvasive } \\
\text { group }(\mathbf{n = 2 6 9 )}\end{array}$ & $\begin{array}{c}\text { pPCI group } \\
(\mathbf{n = 2 5 7 2})\end{array}$ & $\begin{array}{c}\text { p- } \\
\text { value }\end{array}$ \\
\hline Baseline characteristics & & & \\
Age (years) & $76.0(72.0-79.0)$ & $78.0(74.0-82.0)$ & $<0.001$ \\
$70-74$ & $117(43.5 \%)$ & $780(30.3 \%)$ & \\
$75-79$ & $92(34.2 \%)$ & $794(30.9 \%)$ & \\
$\geq 80$ & $60(22.3 \%)$ & $998(38.8 \%)$ & \\
Female sex & $91 / 269(33.8 \%)$ & $935 / 2572(36.4 \%)$ & 0.45
\end{tabular}


Year of inclusion in the registry

2006-2007

2008-2009

2010-2011

2012-2013

2014-2016

Body-mass index $\left(\mathrm{kg} / \mathrm{m}^{2}\right)$

Hypertension

Diabetes mellitus

Dyslipidemia*

Familial history of coronary artery disease

Current smoker

Previous myocardial infarction

Previous coronary artery bypass grafting

Previous percutaneous coronary

intervention

Chronic obstructive pulmonary disease

Previous stroke / transient ischemic attack

Peripheral artery disease

\section{Presentation and initial management}

Cardiac arrest

Anterior myocardial infarction

Q-wave on admission

Killip class III or IV on admission

Serum creatinine on admission $(\mu \mathrm{mol} / \mathrm{l})$

Glycemia on admission ( $\mathrm{mmol} / \mathrm{l})$

Admission to a non-PCI capable hospital

Symptoms onset-to-FMC delay (min)

Symptoms onset-to-FMC delay < $180 \mathrm{~min}$

FMC-to-treatment delay exceeding

guidelines-recommended delay

\section{Risk scores}

GRACE score

\begin{tabular}{ccc} 
& & $<0.001$ \\
$80 / 269(29.7 \%)$ & $295 / 2572(11.5 \%)$ & \\
$72 / 269(26.8 \%)$ & $514 / 2572(20.0 \%)$ & \\
$53 / 269(19.7 \%)$ & $516 / 2572(20.1 \%)$ & \\
$29 / 269(10.8 \%)$ & $571 / 2572(24.7 \%)$ & \\
$35 / 269(13.0 \%)$ & $676 / 2572(26.3 \%)$ & \\
$26.1 \pm 4.1, n=263$ & $25.8 \pm 4.0, n=2461$ & 0.29 \\
$142 / 267(53.2 \%)$ & $1530 / 2562(59.7 \%)$ & 0.045 \\
$33 / 267(12.4 \%)$ & $287 / 2544(11.3 \%)$ & 0.67 \\
$136 / 257(52.9 \%)$ & $1137 / 2493(45.6 \%)$ & 0.03 \\
$51 / 258(19.8 \%)$ & $359 / 2479(14.5 \%)$ & 0.03 \\
$27 / 267(10.1 \%)$ & $198 / 2534(7.8 \%)$ & 0.23 \\
$21 / 269(7.8 \%)$ & $241 / 2563(9.4 \%)$ & 0.45 \\
$4 / 269(1.5 \%)$ & $59 / 2567(2.3 \%)$ & 0.52 \\
$18 / 269(6.7 \%)$ & $291 / 2566(11.3 \%)$ & 0.03 \\
& & \\
$20 / 267(7.5 \%)$ & $177 / 2557(6.9 \%)$ & 0.83 \\
$109 / 268(3.7 \%)$ & $160 / 2559(6.3 \%)$ & 0.13 \\
$14 / 268(5.2 \%)$ & $153 / 2557(6.0 \%)$ & 0.72 \\
& & \\
$1 / 258(0.4 \%)$ & $50 / 2518(2.0 \%)$ & 0.08 \\
$119 / 269(44.2 \%)$ & $1108 / 2572(43.1 \%)$ & 0.76 \\
$107 / 266(40.2 \%)$ & $770 / 2556(30.1 \%)$ & 0.001 \\
$21 / 267(7.9 \%)$ & $195 / 2551(7.6 \%)$ & 0.99 \\
$88(72-103), n=262$ & $85(71-102), n=2533$ & 0.29 \\
$8.0(7.0-10.0), n=252$ & $8.0(6.8-10.0), n=2443$ & 0.68 \\
$139 / 269(51.7 \%)$ & $466 / 2572(18.1 \%)$ & $<0.001$ \\
$85(50-145), n=252$ & $107(60-200), n=2417$ & $<0.001$ \\
$206 / 252(81.7 \%)$ & $1705 / 2417(70.5 \%)$ & $<0.001$ \\
$154 / 259(59.5 \%)$ & $1504 / 2434(61.8 \%)$ & 0.51 \\
& & \\
$70(161-183), n=243$ & $170(157-186), n=2380$ & 0.51 \\
$4.7 \pm 1.7, n=243$ & $5.0 \pm 1.9, n=2296$ & 0.02 \\
\hline
\end{tabular}

TIMI STEMI score

Continuous data are presented as mean \pm standard deviation or median (interquartile range). Categorical variables are presented as numbers (percentage).

*Previous lipid-lowering therapy or known total cholesterol $>2.5 \mathrm{~g} / \mathrm{l}$

$\mathrm{FMC}=$ first medical contact; $\mathrm{pPCI}=$ primary percutaneous coronary intervention; STEMI= ST segment elevation myocardial infarction; TIMI=Thrombolysis In Myocardial Infarction.

\begin{tabular}{lccc}
\hline \multicolumn{4}{c}{ Table 2 - Procedural and in-hospital management of the study population } \\
\hline Variables & $\begin{array}{c}\text { Pharmacoinvasive } \\
\text { group }(\mathbf{n = 2 6 9})\end{array}$ & $\begin{array}{c}\text { pPCI group } \\
(\mathbf{n = 2 5 7 2})\end{array}$ & $\begin{array}{c}\text { p- } \\
\text { value }\end{array}$ \\
\hline Coronary angiogram performed & $256 / 269(95.2 \%)$ & $2572 / 2572(100 \%)$ & $<0.001$ \\
Radial access & $118 / 181(65.2 \%)$ & $1325 / 2209(60.0 \%)$ & 0.18 \\
PCI performed & $213 / 269(79.2 \%)$ & $2572 / 2572(100 \%)$ & $<0.001$ \\
pPCI & - & $2572 / 2572(100 \%)$ & \\
Rescue PCI & $86 / 213(40.4 \%)$ & - & \\
Secondary PCI & $127 / 213(59.6 \%)$ & - & \\
Multivessel disease & $125 / 251(49.8 \%)$ & $1478 / 2567(57.6 \%)$ & 0.02 \\
Significant lesion $(>50 \%)$ & & &
\end{tabular}


Left anterior descending

Left circumflex

Right coronary artery

Left main

Culprit coronary artery

Left anterior descending

Left circumflex

Right

Left main

Stent implantation

Drug-eluting stent

TIMI flow grade 3 after PCI

Additional in-hospital techniques / therapy

Temporary pacemaker

Mechanical circulatory assistances

Mechanical ventilation

Coronary artery bypass grafting

Treatments within first $48 \mathrm{~h}$ of

\section{hospitalization}

Inotropes / vasopressors

Aspirin

Clopidogrel

Ticagrelor

Prasugrel

Vitamin K antagonists

Dual-antiplatelet therapy

Triple therapy

Beta-blockers

ACE inhibitors/ARB

Statins

Categorical variables are presented as numbers (percentage).

$\mathrm{ACE}=$ Angiotensin Converting enzyme; $\mathrm{ARB}=$ Angiotensin Receptor Blockers; other abbreviations as in Table 1 .

\begin{tabular}{ccc}
$172 / 253(68.0 \%)$ & $1888 / 2570(73.5 \%)$ & 0.07 \\
$94 / 253(37.2 \%)$ & $1115 / 2572(43.4 \%)$ & 0.07 \\
$150 / 251(59.8 \%)$ & $1588 / 2569(61.8 \%)$ & 0.57 \\
$13 / 253(5.1 \%)$ & $145 / 2571(5.6 \%)$ & 0.85 \\
& & \\
$116 / 253(45.8 \%)$ & $1106 / 2572(43.0 \%)$ & 0.42 \\
$28 / 253(11.1 \%)$ & $358 / 2572(13.9 \%)$ & 0.24 \\
$108 / 253(42.7 \%)$ & $1073 / 2571(41.7 \%)$ & 0.82 \\
$0 / 253(0.0 \%)$ & $38 / 2572(1.5 \%)$ & 0.04 \\
$203 / 212(95.8 \%)$ & $2268 / 2553(88.8 \%)$ & 0.002 \\
$42 / 212(19.8 \%)$ & $479 / 2553(18.8 \%)$ & 0.78 \\
$198 / 213(93.0 \%)$ & $2309 / 2542(90.8 \%)$ & 0.36 \\
& & \\
$2 / 269(0.7 \%)$ & $38 / 2572(1.5 \%)$ & 0.58 \\
$14 / 269(5.2 \%)$ & $126 / 2572(4.9 \%)$ & 0.94 \\
$13 / 269(4.8 \%)$ & $111 / 2572(4.3 \%)$ & 0.81 \\
$1 / 269(0.4 \%)$ & $6 / 2572(0.2 \%)$ & 0.50 \\
& & \\
$17 / 269(6.3 \%)$ & $258 / 2571(10.0 \%)$ & 0.06 \\
$268 / 269(99.6 \%)$ & $2558 / 2571(99.5 \%)$ & 1.00 \\
$261 / 269(97.0 \%)$ & $1956 / 2571(76.1 \%)$ & $<0.001$ \\
$5 / 269(1.9 \%)$ & $335 / 2572(13.0 \%)$ & $<0.001$ \\
$5 / 269(1.9 \%)$ & $395 / 2572(15.4 \%)$ & $<0.001$ \\
$6 / 269(2.2 \%)$ & $112 / 2561(4.4 \%)$ & 0.14 \\
$264 / 265(99.6 \%)$ & $2533 / 2551(99.3 \%)$ & 0.82 \\
$5 / 266(1.9 \%)$ & $109 / 2561(4.3 \%)$ & 0.09 \\
$197 / 269(73.2 \%)$ & $1906 / 2571(74.1 \%)$ & 0.81 \\
$122 / 269(45.4 \%)$ & $1265 / 2571(49.2 \%)$ & 0.26 \\
$232 / 269(86.2 \%)$ & $2138 / 2571(83.2 \%)$ & 0.23 \\
\hline & &
\end{tabular}

\begin{tabular}{ccc}
$172 / 253(68.0 \%)$ & $1888 / 2570(73.5 \%)$ & 0.07 \\
$94 / 253(37.2 \%)$ & $1115 / 2572(43.4 \%)$ & 0.07 \\
$150 / 251(59.8 \%)$ & $1588 / 2569(61.8 \%)$ & 0.57 \\
$13 / 253(5.1 \%)$ & $145 / 2571(5.6 \%)$ & 0.85 \\
& & \\
$116 / 253(45.8 \%)$ & $1106 / 2572(43.0 \%)$ & 0.42 \\
$28 / 253(11.1 \%)$ & $358 / 2572(13.9 \%)$ & 0.24 \\
$108 / 253(42.7 \%)$ & $1073 / 2571(41.7 \%)$ & 0.82 \\
$0 / 253(0.0 \%)$ & $38 / 2572(1.5 \%)$ & 0.04 \\
$203 / 212(95.8 \%)$ & $2268 / 2553(88.8 \%)$ & 0.002 \\
$42 / 212(19.8 \%)$ & $479 / 2553(18.8 \%)$ & 0.78 \\
$198 / 213(93.0 \%)$ & $2309 / 2542(90.8 \%)$ & 0.36 \\
& & \\
$2 / 269(0.7 \%)$ & $38 / 2572(1.5 \%)$ & 0.58 \\
$14 / 269(5.2 \%)$ & $126 / 2572(4.9 \%)$ & 0.94 \\
$13 / 269(4.8 \%)$ & $111 / 2572(4.3 \%)$ & 0.81 \\
$1 / 269(0.4 \%)$ & $6 / 2572(0.2 \%)$ & 0.50 \\
& & \\
$17 / 269(6.3 \%)$ & $258 / 2571(10.0 \%)$ & 0.06 \\
$268 / 269(99.6 \%)$ & $2558 / 2571(99.5 \%)$ & 1.00 \\
$261 / 269(97.0 \%)$ & $1956 / 2571(76.1 \%)$ & $<0.001$ \\
$5 / 269(1.9 \%)$ & $335 / 2572(13.0 \%)$ & $<0.001$ \\
$5 / 269(1.9 \%)$ & $395 / 2572(15.4 \%)$ & $<0.001$ \\
$6 / 269(2.2 \%)$ & $112 / 2561(4.4 \%)$ & 0.14 \\
$264 / 265(99.6 \%)$ & $2533 / 2551(99.3 \%)$ & 0.82 \\
$5 / 266(1.9 \%)$ & $109 / 2561(4.3 \%)$ & 0.09 \\
$197 / 269(73.2 \%)$ & $1906 / 2571(74.1 \%)$ & 0.81 \\
$122 / 269(45.4 \%)$ & $1265 / 2571(49.2 \%)$ & 0.26 \\
$232 / 269(86.2 \%)$ & $2138 / 2571(83.2 \%)$ & 0.23 \\
\hline & &
\end{tabular}

Table 3 - In-hospital outcomes of the study population

\begin{tabular}{lccc}
\hline Outcomes & $\begin{array}{c}\text { Pharmacoinvasive } \\
\text { group }(\mathbf{n = 2 6 9})\end{array}$ & $\begin{array}{c}\text { pPCI group } \\
(\mathbf{n = 2 5 7 2})\end{array}$ & $\begin{array}{c}\text { p- } \\
\text { value }\end{array}$ \\
\hline Major adverse cardiovascular events & $31 / 269(11.5 \%)$ & $270 / 2572(10.5 \%)$ & 0.68 \\
All-cause death & $25 / 269(9.3 \%)$ & $232 / 2572(9.0 \%)$ & 0.97 \\
Cardiovascular death & $22 / 269(8.2 \%)$ & $222 / 2572(8.6 \%)$ & 0.89 \\
Non-fatal myocardial infarction & $4 / 269(1.5 \%)$ & $22 / 2572(0.9 \%)$ & 0.30 \\
Stent thrombosis & $1 / 269(0.4 \%)$ & $27 / 2572(1.0 \%)$ & 0.51 \\
Stroke & $4 / 269(1.5 \%)$ & $12 / 2572(0.5 \%)$ & 0.06 \\
BARC 3 or 5 major bleeding & $6 / 86(7.0 \%)$ & $64 / 1438(4.5 \%)$ & 0.28 \\
Intracranial hemorrhage & $2 / 86(2.3 \%)$ & $4 / 1438(0.3 \%)$ & 0.04 \\
Net adverse clinical events* & $15 / 86(17.4 \%)$ & $199 / 1438(13.8 \%)$ & 0.44 \\
Development of Killip class III or IV HF & $9 / 267(3.4 \%)$ & $220 / 2546(8.6 \%)$ & 0.004 \\
Sustained ventricular arrhythmias & $14 / 269(5.2 \%)$ & $180 / 2572(7.0 \%)$ & 0.33 \\
New-onset atrial fibrillation & $18 / 269(6.7 \%)$ & $278 / 2572(10.8 \%)$ & 0.046 \\
High-degree atrioventricular block & $9 / 269(3.3 \%)$ & $147 / 2572(5.7 \%)$ & 0.14
\end{tabular}


Mechanical complications

Right ventricular infarction

Left ventricular ejection fraction (\%)

Intensive care unit length of stay ${ }^{\dagger}$ (days)

Hospital length of stay ${ }^{\dagger}$ (days)

\begin{tabular}{ccc}
$11 / 269(4.1 \%)$ & $128 / 2572(5.0 \%)$ & 0.62 \\
$6 / 269(2.2 \%)$ & $74 / 2572(2.9 \%)$ & 0.68 \\
$48.6 \pm 11.8, n=242$ & $47.6 \pm 11.6, n=2385$ & 0.48 \\
$4.0(3.0-5.0), n=243$ & $4.0(3.0-5.0), n=2333$ & 0.97 \\
$5.0(4.0-7.0), n=243$ & $6.0(5.0-8.0), n=2336$ & $<0.001$ \\
\hline
\end{tabular}

BARC $=$ Bleeding Academic Research Consortium; HF= Heart Failure

*Net adverse clinical events defined as the composite of major adverse cardiovascular events or BARC 3 or 5 bleeding and calculated among patients with data regarding in-hospital BARC defined bleeding events

$\dagger$ Excluding in-hospital death

\begin{tabular}{lccc}
\hline \multicolumn{4}{c}{ Table 4-In-hospital outcomes of the matched cohort } \\
\hline Outcomes & $\begin{array}{c}\text { Pharmacoinvasive } \\
\text { group }(\mathbf{n = 2 4 7})\end{array}$ & $\begin{array}{c}\text { pPCI group } \\
(\mathbf{n = 9 5 8})\end{array}$ & $\begin{array}{c}\text { p- } \\
\text { value }\end{array}$ \\
\hline Major adverse cardiovascular events & $28 / 247(11.3 \%)$ & $86 / 958(9.0 \%)$ & 0.26 \\
All-cause death & $25 / 247(10.1 \%)$ & $70 / 958(7.3 \%)$ & 0.18 \\
Cardiovascular death & $22 / 247(8.9 \%)$ & $68 / 958(7.1 \%)$ & 0.34 \\
Non-fatal myocardial infarction & $2 / 247(0.8 \%)$ & $8 / 958(0.8 \%)$ & 1.00 \\
Stent thrombosis & $1 / 247(0.4 \%)$ & $8 / 958(0.8 \%)$ & 0.70 \\
Stroke & $3 / 247(1.2 \%)$ & $5 / 958(0.5 \%)$ & 0.21 \\
BARC 3 or 5 major bleeding & $6 / 86(7.0 \%)$ & $16 / 391(4.1 \%)$ & 0.26 \\
Intracranial hemorrhage & $2 / 86(2.3 \%)$ & $0 / 391(0.0 \%)$ & 0.03 \\
Net adverse clinical events* & $15 / 86(17.4 \%)$ & $52 / 421(12.4 \%)$ & 0.26 \\
Development of Killip class III or IV HF & $8 / 246(3.3 \%)$ & $88 / 951(9.3 \%)$ & 0.002 \\
Sustained ventricular arrhythmias & $14 / 247(5.7 \%)$ & $61 / 958(6.4 \%)$ & 0.69 \\
New-onset atrial fibrillation & $18 / 247(7.3 \%)$ & $109 / 958(11.4 \%)$ & 0.062 \\
High-degree atrioventricular block & $9 / 247(3.6 \%)$ & $54 / 958(5.6 \%)$ & 0.21 \\
Mechanical complications & $11 / 247(4.5 \%)$ & $46 / 958(4.8 \%)$ & 0.82 \\
Right ventricular infarction & $6 / 247(2.4 \%)$ & $19 / 958(2.0 \%)$ & 0.66 \\
Left ventricular ejection fraction $(\%)^{\dagger}$ & $49.2 \pm 11.6, n=222$ & $48.0 \pm 11.4, n=890$ & 0.15 \\
Intensive care unit length of stay ${ }^{\dagger}$ (days) & $4.0(3.0-5.0), n=245$ & $4.0(3.0-5.0), n=954$ & 0.45 \\
Hospital length of stay ${ }^{\dagger}$ (days) & $5.0(3.0-7.0), n=245$ & $6.0(5.0-8.0), n=954$ & $<0.001$ \\
\hline BARC= Blat
\end{tabular}

BARC $=$ Bleeding Academic Research Consortium; HF: Heart Failure

* Net adverse clinical events defined as the composite of major adverse cardiovascular events or BARC 3 or 5 bleeding and calculated among patients with data regarding in-hospital BARC defined bleeding events 